\title{
Avaliação da sexualidade em paciente adulta com hiperplasia adrenal congênita forma clássica não-perdedora de sal: relato de caso
}

\section{Sexuality assessment in an adult with non-salt-wasting classic form of congenital adrenal hyperplasia: case report}

Ana Alice Silva Amaral ${ }^{1}$. Elisa Santos Lopes ${ }^{1}$. Zenilda Vieira Bruno². Débora Fernandes Britto ${ }^{3}$.

1 Universidade Federal do Ceará (UFC), Fortaleza, Ceará, Brasil. 2 Universidade Federal do Ceará (UFC), Maternidade Escola Assis Chateaubriand (MEAC), Fortaleza, Ceará, Brasil. 3 Maternidade Escola Assis Chateaubriand (MEAC), Fortaleza, Ceará, Brasil.

\section{RESUMO}

A hiperplasia adrenal congênita (HAC) é uma doença autossômica recessiva, que pode levar a alterações hormonais desde o início do desenvolvimento endocrinológico. As pacientes femininas com HAC com ambiguidade genital foram submetidas a um processo de virilização da genitália externa devido aos altos níveis de androgênios circulantes durante o desenvolvimento embrionário. Relatamos o caso de uma paciente com HAC e genitália ambígua submetida a cirurgias de correção genital e estudamos a sua sexualidade por meio da anamnese e do uso de um instrumento para avaliar a função sexual feminina em toda sua complexidade, o Índice de Função Sexual Feminina (Female Sexual Function Index- FSFI). Foi encontrado uma disfunção sexual importante e comparamos os dados obtidos com a literatura, obtendo notórias confirmações da importância do suporte psicológico, familiar e social para a saúde sexual da paciente com HAC, além do tratamento cirúrgico e hormonal.

Palavras-chave: Hiperplasia suprarrenal congênita. Sexologia. Sexualidade.

\section{ABSTRACT}

The congenital adrenal hyperplasia $(\mathrm{CAH})$ is an autosomal recessive disorder that may lead to hormonal problems, beginning with the intrauterine development. Women with $\mathrm{CAH}$ with ambiguous genitalia were exposed to high levels of androgens during the embryological life. We report the case of a patient with CAH and genital ambiguity submitted to surgical genital repair and we studied her sexuality, using the Female Sexual Function Index (FSFI), a well-known questionnaire to access the complex female sexual life. The patient was diagnosed with a sexual dysfunction and the acquired data was compared with the medical literature. We obtained data that confirms the importance of a psychological, familiar and social support to assure a healthy sexual life for the patient with $\mathrm{CAH}$, as well as the surgical and hormonal therapy.

Keywords: Congenital adrenal hyperplasia. Sexology. Sexuality.

Autor correspondente: Ana Alice Silva Amaral, Rua Martinho Rodrigues, 1201, Fátima, Fortaleza, Ceará. CEP: 60415-160. Telefone: +55 85 99818-1817. E-mail: anaalicepalha@hotmail.com

Conflito de interesses: Não há qualquer conflito de interesses por parte de qualquer um dos autores.

Recebido em: 25 Mar 2018; Revisado em: 14 Jun 2018; Aceito em: 01 Set 2018. 


\section{INTRODUÇÃO}

A hiperplasia adrenal congênita (HAC) é uma doença autossômica recessiva, que em cerca de 95\% das vezes decorre de mutações no gene CYP21A2, que, por sua vez, codifica a enzima 21-hidroxilase. A deficiência dessa enzima compromete a produção de corticosteroides, o que gera um aumento nos níveis de androgênios. Há diferentes graus de deficiência da enzima dependentes do grau de mutações no gene, o que implica em diversos níveis de androgênios e, consequentemente, diferentes formas clínicas. $^{1,2}$

Do ponto de vista ginecológico, algumas pacientes femininas com HAC sofrem de ambiguidade genital após um processo de virilização da genitália devido aos altos níveis de androgênios séricos. ${ }^{3,4}$ Essa ambiguidade genital varia de acordo com o comprometimento enzimático e pode ser classificada clinicamente utilizando a escala de Prader, segundo a aparência da genitália externa. ${ }^{2,5}$

Mesmo após procedimentos cirúrgicos e terapias farmacológicas precoces, as pacientes com HAC necessitam de acompanhamento médico e suporte psicológico regulares de modo a controlar comorbidades comuns. Dentre essas comorbidades, os distúrbios sexuais ganham destaque devido ao impacto que geram na qualidade de vida, podendo estar associados com problemas psiquiátricos, como depressão e ansiedade. ${ }^{1,6}$

$\mathrm{O}$ presente relato mostra o caso de uma paciente adulta com diagnóstico prévio de HAC forma clássica não-perdedora de sal submetida a cirurgias para correção de genitália ambígua. Após seis meses da última cirurgia, a paciente realizou uma avaliação de sua sexualidade, utilizando o Índice de Função Sexual Feminina (Female Sexual Function Index- FSFI). ${ }^{7,8} \mathrm{~A}$ partir do exame clínico e do uso do FSFI, foram obtidos dados que mostram características da sexualidade dessa paciente em seus diferentes aspectos.

\section{RELATO DE CASO}

Paciente de 20 anos, sexo feminino, confusa em relação à sua orientação sexual, referindo história de relações homossexuais irregulares e tentativas frustradas de relações com penetração vaginal com homens, acompanhada no serviço de Endocrinologia do Hospital Universitário Walter Cantídio (HUWC) por HAC clássica forma não-perdedora de sal, foi encaminhada ao ambulatório de Ginecologia do mesmo hospital. O histórico cirúrgico prévio inclui clitoridectomia e abertura do canal vaginal na infância. Apesar disso, a paciente persistiu com queixa de constrangimento causado pelo clitóris aumentado, além de dispareunia. No histórico familiar, ganha destaque a consanguinidade dos pais.

$\mathrm{Na}$ inspeção da vulva, foi observado o clitóris aumentado com cerca de $2.5 \mathrm{~cm}$ (Figura 1). Além disso, foi constatado uma vagina estreita e a ausência de pequenos lábios (Figura 2). $\mathrm{O}$ exame especular e o toque vaginal não foram realizados devido à estenose vaginal.
A conduta realizada foi o encaminhamento da paciente para tratamento cirúrgico, sendo, posteriormente, submetida à vaginoplastia com cistoscopia, vaginoscopia e histeroscopia em novembro de 2015. A clitoridectomia foi realizada em junho de 2016 sem intercorrências. A paciente permaneceu em seguimento ambulatorial, utilizando moldes vaginais e mostrando resultados cirúrgicos satisfatórios com a possibilidade de passagem de espéculo e de toque vaginal após três meses (Figuras 3 e 4).

Figura 1. Achado de clitoromegalia.

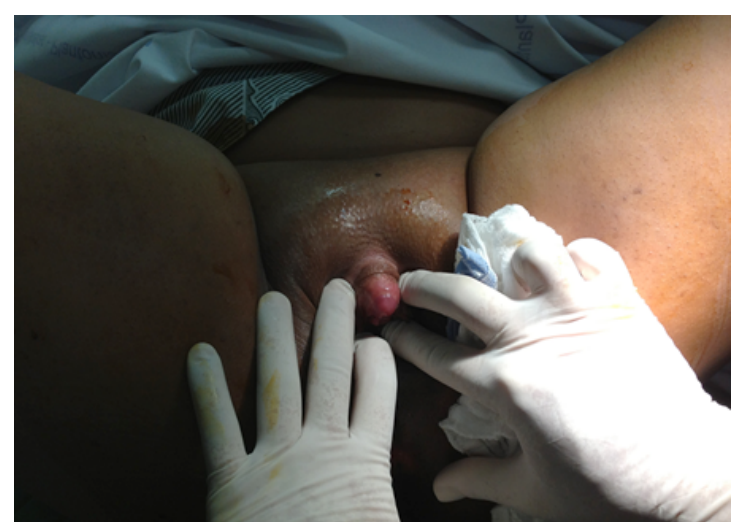

Figura 2. Ausência de pequenos lábios.

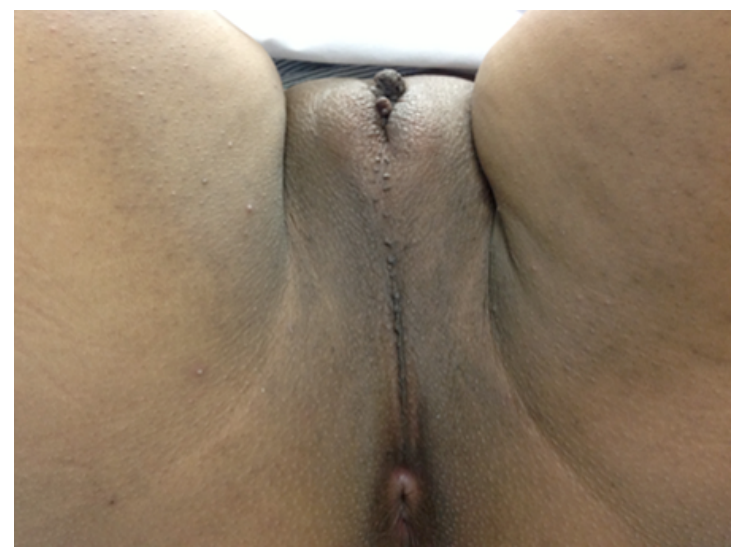

Figura 3. Canal vaginal permitindo passagem de espéculo pequeno pós-correção cirúrgica.

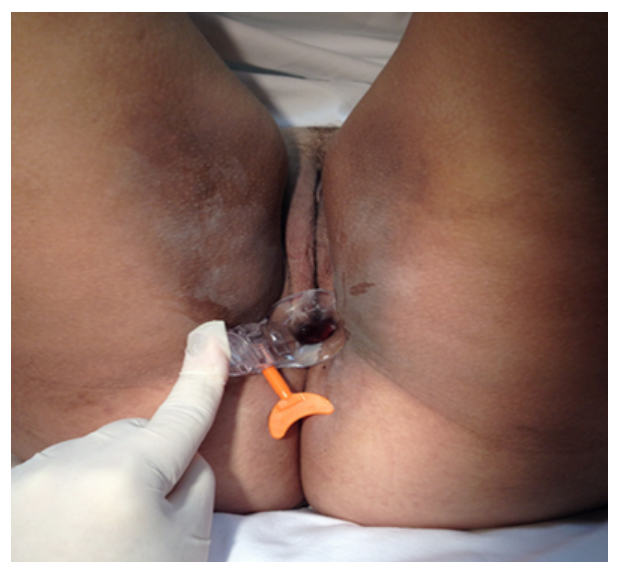


Figura 4. Canal vaginal acessível ao toque vaginal pós-correção cirúrgica.

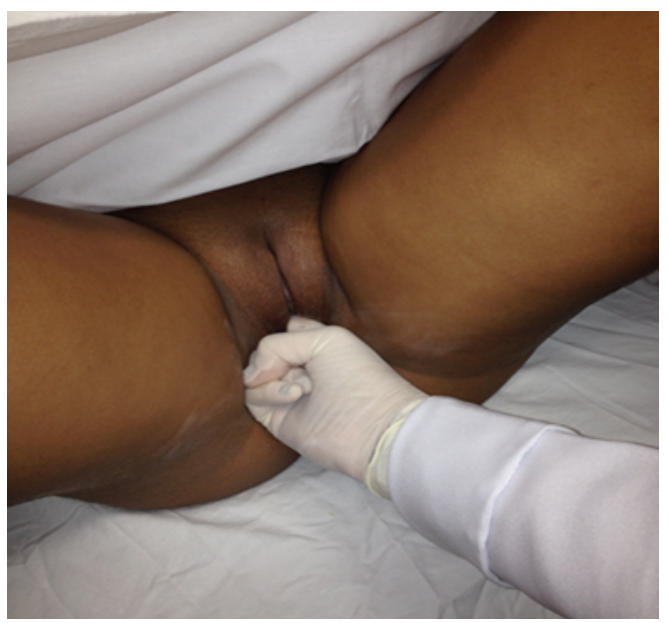

\section{METODOLOGIA}

O FSFI, questionário mundialmente utilizado para avaliar a sexualidade feminina de forma multidimensional, foi utilizado para detalhar as informações relacionadas à vida sexual da paciente após seis meses do último procedimento cirúrgico.

O instrumento é composto por 19 questões, abordando desejo, excitação, lubrificação, orgasmo e resolução. Dentro das questões, seis dimensões da sexualidade feminina são abordadas: libido, excitação, lubrificação genital, orgasmo, satisfação sexual final e dor sexual. A pontuação de cada questão varia de 0 ou 1 a 5 . O cálculo dos escores de avaliação foi produzido de acordo com os domínios do ciclo de atividade sexual feminina, portanto, cada um desses domínios possui questões próprias, cujos escores são calculados separadamente por fatores de multiplicação próprios, como mostrado no Quadro 1.7-9

A pontuação final consiste na soma de todos os escores correspondentes a cada domínio da sexualidade feminina. $\mathrm{O}$ ponto de corte originalmente sugerido foi o de 26 pontos. Mulheres com pontuação igual ou inferior a esse valor são consideradas portadoras de alguma disfunção sexual. ${ }^{8} \mathrm{O}$ trabalho foi submetido ao Comitê de Ética em pesquisa, garantindo o sigilo médico e foi realizada a explicação das definições do questionário, evitando confusões terminológicas.

Quadro 1. Escores de avaliação por domínios.

\begin{tabular}{|l|l|l|l|l|l|}
\hline \multicolumn{7}{|c|}{ Escores de avaliação do FSFI } \\
\hline Domínio & Questões & Variação de Escore & Fator de Multiplicação & Escore Mínimo & Escore Máximo \\
\hline Desejo & 1,2 & $1-5$ & 0,6 & 1,2 & 6,0 \\
\hline Excitação & $3,4,5,6$ & $0-5$ & 0,3 & 0,0 & 6,0 \\
\hline Lubrificação & $7,8,9,10$ & $0-5$ & 0,3 & 0,0 & 6,0 \\
\hline Orgasmo & $11,12,13$ & $0-5$ & 0,4 & 0,0 & 6,0 \\
\hline Satisfação & $14,15,16$ & 0 (ou 1)-5* & 0,4 & 0,8 & 6,0 \\
\hline Dor & $17,18,19$ & $0-5$ & 0,4 & 0,0 & 6,0 \\
\hline
\end{tabular}

*Questão 14 varia de 0-5; questões 15 e 16 variam de 1-5.

Adaptado de: Pacagnella R, Martinez EZ, Vieira EM. Validade de construto de uma versão em português do female sexual function index. Cad Saude Pública. 2009;25(11):2333-44.

\section{RESULTADOS}

A correção dos defeitos anatômicos possibilitaria à paciente um progresso em sua vida sexual dificultada pela genitália ambígua. Para avaliar melhor esse possível progresso, a paciente respondeu ao instrumento FSFI, obtendo o escore total de 21,8. Essa pontuação indica uma disfunção sexual.

O domínio "Desejo" está relacionado às duas primeiras questões. Nesse domínio, a paciente obteve pontuação máxima. O segundo domínio avaliado é a "Excitação sexual", que corresponde às questões 3 a 6 . A paciente obteve a melhor pontuação possível nas questões 3,4 e 6 . Contudo, a pontuação da paciente no domínio da excitação não foi a máxima, pois indicou na questão 5 "Segurança muito baixa ou sem segurança" para ficar excitada, pontuando 4,8 no segundo domínio.
O terceiro domínio é a lubrificação e é avaliado pelas questões 7 a 10. Nas questões 7, 8 e 9 a paciente obteve escore máximo. Contudo, a pontuação nesse domínio foi apenas 5,4, pois, na questão 10, a paciente indicou ser "Difícil" manter a lubrificação até o fim da atividade ou ato sexual.

No quarto domínio, a paciente obteve um baixo escore de 2,8 ao indicar na questão 11 que "Quase nunca ou nunca" atingiu o orgasmo após estímulo ou ato sexual, assinalar, na questão 12, que foi "Ligeiramente difícil" atingir o orgasmo após estímulo ou ato sexual e que se considera "Moderadamente insatisfeita" em sua capacidade de atingir o orgasmo. A satisfação sexual é o quinto domínio avaliado pelo FSFI e está relacionado às questões 14 a 16 . Nesse domínio, a paciente também obteve um escore baixo "2,8" após indicar que esteve "Moderadamente satisfeita" com a proximidade emocional 
entre ela e o parceiro durante a atividade sexual e que esteve "Muito insatisfeita" com o relacionamento sexual com o parceiro durante as últimas 4 semanas. Além disso, na questão 16 , a paciente indica que esteve "Moderadamente insatisfeita" com sua vida sexual nesse mesmo período.

O último domínio avaliado é a dor durante o sexo. Esse foi o domínio com a pior pontuação (zero), pois a paciente não tentou coito vaginal após as últimas duas cirurgias.

\section{DISCUSSÃO}

A forma clássica não perdedora de sal da HAC possui graus variados de genitália ambígua. A genética é um fator de importância, e por se tratar de uma enfermidade recessiva, o fato dos pais da paciente possuírem consanguinidade é relevante. A correlação entre o grau de genitália ambígua e o grau de mutação também é relevante para nosso caso ao observar que antes das cirurgias realizadas em 2015 e em 2016, a paciente era classificada na escala de Prader como grau II devido a clitoromegalia e a fusão labial posterior, portanto, a paciente possuía um grau baixo de Prader provavelmente decorrente de um comprometimento baixo a moderado do gene CYP21A2. Pacientes com graus menores de Prader possuem um potencial maior para uma vida sexual saudável. . $^{50}$

Nossa paciente relatou não saber sua orientação sexual com certeza. Essa confusão pode estar relacionada a uma condição psiquiátrica que mostrou relação considerável em pacientes com HAC, a disforia de gênero. ${ }^{3}$

A disfunção indicada pelo FSFI foi principalmente decorrente do baixo escore nos últimos três domínios avaliados pelo

\section{REFERÊNCIAS}

1. Nordenström A, Frisén L, Falhammar H, Filipsson H, Holmdahl G, Janson P, et al. Sexual function and surgical outcome in women with congenital adrenal hyperplasia due to CYP21A2 deficiency: clinical perspective and the patients' perception. J Clin Endocrinol Metab. 2010;95(8):3633-40.

2. Frisén L, Nordenström A, Falhammar H, Filipsson H, Holmdahl G, Janson P, et al. Gender role behavior, sexuality, and psychosocial adaptation in women with congenital adrenal hyperplasia due to CYP21A2 deficiency. J Clin Endocrinol Metab. 2009;94(9):3432-9.

3. Pasterski V, Zucker KJ, Hindmarsh PC, Hughes IA, Acerini C, Spencer D, et al. Increased cross-gender identification independent of gender role behavior in girls with congenital adrenal hyperplasia: results from a standardized assessment of 4-to 11-year-old children. Arch Sex Behav. 2015;44:1363-75.

4. Parsa AA, New MI . Steroid 21-hydroxylase deficiency in congenital adrenal hyperplasia. J Steroid Biochem Mol Biol. 2017;165(PtA):2-11.

5. González R, Ludwikowski BM. Should CAH in females be classified as DSD? Front Pediatr. 2016;4:48.

\section{Como citar:}

Amaral AA, Lopes ES, Bruno ZV, Britto DF. Avaliação da sexualidade em paciente adulta com hiperplasia adrenal congênita forma clássica nãoperdedora de sal: relato de caso. Rev Med UFC. 2019 abr-jun;59(2):50-53. questionário. A paciente mostrou ser difícil obter orgasmo e satisfação sexual em suas relações. A sua insegurança sexual e confusão relacionadas à orientação sexual foram evidentes em sua anamnese, o que pode justificar a sua insatisfação com a sexualidade. Importante salientar que a paciente relatou dispareunia em suas tentativas de penetração vaginal devido à estenose vaginal antes das cirurgias recentes, o que pode influenciar a sua insegurança sexual.

A melhoria da vida sexual do paciente não é restrita à correção anatômica de sua genitália. Suporte psicológico é essencial para pacientes com disfunção sexual e portadoras de HAC, seja este farmacológico ou não. Esse suporte inclui também o apoio familiar, que mostrou ser decisivo para uma vida sexual saudável em pacientes com HAC., ${ }^{3,6}$

\section{CONCLUSÃO}

O impacto causado pela genitália ambígua causada pela HAC vai muito além da estética e da anatomia genital, considerando que a sexualidade feminina é multidimensional. A insegurança sexual mostrou bastante influência na atividade da paciente, que, apesar de possuir atualmente uma genitália feminina funcional e apta para o coito, possui grande resistência ao ato sexual, embora o desejo, excitação e lubrificação estejam preservados. A orientação sexual mostrou ser outro fator que gera insegurança para a paciente. Tais dificuldades psíquicas relacionadas à sexualidade das pacientes com HAC e genitália ambígua mostraram-se com uma significativa prevalência e são bem documentadas na literatura, que por sua vez, mostra que o suporte psicológico, social e familiar tem grande relevância na restauração da vida sexual saudável para a paciente.

6. Kanhere M, Fuqua J, Rink R, Houk C, Mauger D, Lee PA. Psychosexual development and quality of life outcomes in females with congenital adrenal hyperplasia. Int $\mathrm{J}$ Pediatr Endocrinol. 2015;2015:21

7. Pacagnella R, Martinez EZ, Vieira EM. Validade de construto de uma versão em português do female sexual function index. Cad Saude Pública. 2009;25(11):2333-44.

8. Rosen R, Brown C, Heiman J, Leiblum S, Meston C, Shabsigh R, et al. The Female Sexual Function Index (FSFI): a multidimensional self-report instrument for the assessment of female sexual function. J Sex Marital Ther. 2000;26(2):191-208.

9. Masters WH, Johnson VE. Human sexual response. Boston: Little Brown; 1966.

10. Gastaud F, Bouvattier C, Duranteau L, Brauner R, Thibaud $\mathrm{E}$, Kutten $\mathrm{F}$, et al. Impaired sexual and reproductive outcomes in women with classical forms of congenital adrenal hyperplasia. J Clin Endocrinol Metab. 2007;92:1391-6. 